\title{
PCR-based Approaches for Detection of Mutated ras Genes
}

\author{
Alphonsus D.M. van Mansfeld 1,2 and Johannes L. Bos' \\ ${ }^{1}$ Laboratory for Physiological Chemistry and ${ }^{2}$ Institute of Molecular Biology and \\ Medical Biotechnology, University of Utrecht, 3521 GG Utrecht,
} The Netherlands

$\mathbf{T}$ he ras genes encode $21-\mathrm{kD}$ GTPbinding proteins $\left(\mathrm{p} 21^{\text {ras}}\right)$ that cycle between an inactive GDP-bound form and an active GTP-bound form. The p21 ${ }^{\text {ras }}$ proteins are thought to play an important role in signal transduction that eventually controls proliferation and differentiation of many different cells. The ras(proto-onco)genes can be activated as oncogenes by simple point mutations, which substitute a single amino acid residue at a critical position in the protein product. Mutated ras genes occur with a high frequency in common human cancers, including adenocarcinoma of the lung, colorectal cancer, myeloid leukemia, and adenocarcinoma of the pancreas. ${ }^{(1)}$

Originally, the transforming ras mutations were determined by transfection of NIH-3T3 cells, followed by cloning and sequencing of the oncogene. The mutations found are almost without exception point mutations at codons 12,13 , or 61 of the highly homologous ras genes $\mathrm{H}$-ras, $\mathrm{K}$ ras, and $\mathrm{N}$-ras. The introduction of the polymerase chain reaction (PCR) technique has greatly simplified the procedure for analyzing tumors for the presence of one of these point mutations. A source for the DNA to be analyzed may be either fresh or frozen tissue samples. Also formalin-fixed, paraffin-embedded tissue sections may be used as starting material, allowing retrospective analysis of archival material. Different methods have been devised to detect the common point mutations in the PCR-amplified ras gene segments, as shown in Table 1 . We will discuss these different methods in this review.

\section{Allele-specific Oligonucleotide Hybridization}

Allele-specific oligonucleotide hybridization (ASO) to detect point mutations is based on the fact that an oligonucleotide with one mismatch binds more weakly to its (imperfect) complement than a perfectly matching one. By performing hybridization and washing just below the dissociation temperature $\left(T_{\mathrm{m}}\right)$ of the perfectly matching oligonucleotide, one can discriminate between a perfectly matching oligonucleotide and an oligonucleotide with 1bp mismatch. ${ }^{(2)}$ In short, PCR-amplified DNA is spotted onto a nylon (or nitrocellulose) filter and hybridized to a radioactively labeled oligonucleotide which corresponds to the wild-type sequence of the particular ras codons. The filter is washed under stringent conditions and hybridization is detected by autoradiography. This procedure detects the presence of the wildtype allele of the gene segment. Duplicate filters are then hybridized with different, labeled oligonucleotides, each of which corresponds to one of the expected point mutations in the gene segment. Hybridization of one of these allele-specific (point mutationspecific) oligonucleotides shows the presence of the corresponding point mutation. Hybridization and stringent washing may be performed in the presence of $3 \mathrm{M}$ tetramethylammonium chloride. (3) At this concentration the G-C and A-T base pairs have similar stabilities, so that oligonucleotides of the same length have the same $T_{m}$, regardless of the base composition. This allows hybridization and washing of the filters with different oligonucleotides next to each other in one procedure. Using this method, large series of DNA samples can be analyzed in a short period of time for the presence of anticipated point mutations. This method has been applied in numerous studies in which tumors were examined for the presence of ras gene mutations. ${ }^{(1)}$

TABLE 1 Detection of Common Point Mutations in PCR-amplified ras Gene Segment

\begin{tabular}{lc}
\hline Tissue $\rightarrow$ DNA $\rightarrow$ PCR & $\begin{array}{c}\text { Nature of the } \\
\text { mutation }(+/-)^{\mathrm{a}}\end{array}$ \\
\hline Allele-specific oligonucleotide hybridization & + \\
RNase mismatch cleavage & - \\
Single-strand conformation polymorphism & - \\
DNA sequence analysis & + \\
(Primer-mediated) RFLP & $-1+$ \\
Mutant-enriched PCR & - \\
Allele-specific PCR & + \\
\hline
\end{tabular}

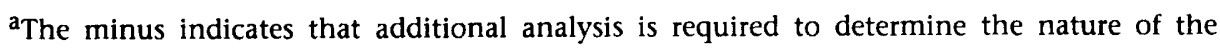
mutation. See text for references. 
Recently, a reverse oligonucleotide hybridization method has been developed. ${ }^{(4)}$ Oligonucleotide probes are immobilized on nylon filters through a covalent binding reaction and PCR products are hybridized to the oligonucleotide probes. PCR products were labeled with biotin using biotinylated primer oligonucleotides. In combination with a chemiluminescent detection system, this yields a very sensitive nonradioactive procedure. This approach allows the simultaneous hybridization of one PCR-amplified DNA sample to a large number of different oligonucleotide probes.

\section{RNase Mismatch Cleavage}

The RNase mismatch cleavage procedure can detect the position of a mutation in the target DNA. ${ }^{(5,6)}$ The method involves hybridization of a radioactively labeled wild-type RNA probe to PCR-amplified DNA, which may contain a mutation. RNase A will cleave the RNA at the position of a mismatch. The resulting RNA fragments are analyzed by gel electrophoresis and the lengths of the fragments give the position of the mutation. Certain mismatches in the DNA : RNA heteroduplexes are quite RNase-resistant, $(5,6)$ requiring that the complementary strands, which give the RNase-sensitive mismatch pair, also be analyzed. Further analysis is required to establish the nature of the mutation. Winter et al. ${ }^{(6)}$ have developed this method to study the amplification and expression of the human mutant K-ras gene, using DNA and RNA isolated from tumor cell lines. Almoguera et al. ${ }^{(7)}$ and Perucho et al. ${ }^{(8)}$ have applied this method to PCR-amplified DNA from formalinfixed, paraffin-embedded samples from biopsies, surgical resections, and autopsies.

\section{Single-Strand Conformation Polymorphism}

Hayashi and co-workers ${ }^{(9-11)}$ have devised a method, single-strand conformation polymorphism (SSCP), to detect mutations in DNA that is based on conformation polymorphism of the separated single strands of PCR products. First, the target sequence in genomic DNA or cDNA is amplified and simultaneously labeled using radioactively labeled PCR primers or
dNTPs. Subsequently, the PCR product is denatured and analyzed by electrophoresis on a non-denaturing polyacrylamide gel. Mutations are detected by altered mobility of the separated strands relative to the strands of the normal, wild-type PCR product. This approach shows structural alterations, including point mutations in the PCR products. This method has been used to study ras gene mutations in human lung cancer. ${ }^{(12)}$ It was shown that the 10 different point mutations examined after amplification in $100-$ to $200-b p$ fragments could all be detected by significant mobility shifts in at least one of the separated strands. The mutations can be elucidated by isolation of each polymorphic DNA band from the gel and amplification by a second PCR for sequence determination. By this technique, the sequence of a minor constituent (approximately 3\%) can be determined accurately. ${ }^{(13)}$ A nonradioactive SSCP is described by Ainsworth et al., (14) who performed an asymmetric amplification on PCR-amplified products and detected polymorphic DNA products by silver staining.

\section{DNA Sequence Analysis}

Sequence analysis of PCR-amplified DNA represents the most definitive method for the identification of (point) mutations. Also, mutations in the amplified segment that had not been anticipated can be detected. However, the mutant sequence can only be read in the combined wild-type and mutant sequence ladder if the mutant allele is present at a certain minimal percentage. Methods that detect mutations but not the exact nature of the mutation [for example SSCP and restriction fragment length polymorphism (RFLP) analysis (see below)] frequently use characterization of the mutation by sequence analysis. Sequence analysis of PCR-amplified DNA has been used widely to study ras gene mutations in different tumors, ${ }^{(15-18)}$ and different approaches (see, for example, refs. 15, 19, and 20) have been followed. A method by which gelpurified PCR products can be sequenced directly ${ }^{(21)}$ allows easy and fast characterization of products of RFLP analyses.

Important for clinical use are methods that facilitate the linking of en- zymatic amplification to automatic sequencing. This can be reached by incorporation of biotin in one of the amplification primers. The PCR products can be isolated easily using avidin- or streptavidin-agarose or magnetic beads coated with streptavidin. $(22,23)$ The two strands of the PCR products can then be separated by denaturation with alkali and sequenced. Shaw et al. ${ }^{(24)}$ have applied this approach to study K-ras mutations in primary colon tumors.

Syvänen et al. ${ }^{(25)}$ have developed a solid-phase minisequencing method. The PCR-amplified DNA fragment is immobilized using a biotinylated primer and streptavidin-coated magnetic beads. The nonbiotinylated strand is removed by denaturation with alkali. Mutations are identified in primer extension reactions with a primer that has its $3^{\prime}$ end next to the position where a mutation can occur. Four separate primer extension reactions, each with one of the four radiolabeled dNTPs, are performed. Incorporation of a particular nucleotide then shows the presence of its complement in the immobilized template strand. The method has been used to study $\mathrm{N}$-ras mutations in acute myeloid leukemia and has identified a mutant ras allele in a sample that consisted of $99.7 \%$ normal cells.

Multiplex PCR amplification and direct sequencing of the homologous ras sequences have been described by Manam and Nichols. ${ }^{(26)}$ In this procedure, the regions surrounding codons 12-13 and 61 of the three ras genes are amplified simultaneously. Each of the amplified ras segments in this mixture is then sequenced separately using high-stringency annealing and extension of the specific sequence primer permitted by Taq polymerase.

\section{Restriction Fragment Length Polymorphism}

The presence of a point mutation in a certain DNA segment can create or destroy a restriction enzyme recognition site and thus result in an RFLP. For example, the polymorphism for the enzyme HpaII, which is the result of any change in the first or the second nucleotide of codon 12 of $\mathrm{H}-$ ras, $^{(27)}$ has been used to detect point mutations at 
these positions in PCR-amplified DNA. ${ }^{(28)}$ Analysis of the PCR products after restriction enzyme incubation, gel electrophoresis, and staining with ethidium bromide directly shows whether the anticipated point mutation is present or not. Nakazawa et al. ${ }^{(29)}$ have developed a sensitive method to detect an $\mathrm{A}$ to $\mathrm{T}$ mutation at codon 61 of $\mathrm{H}$-ras; this transversion results in an $\mathrm{Xbal}$ cleavage site. PCR amplification was performed using radioactively labeled oligonucleotide primers and T7 DNA polymerase. Presence of the radioactive fragment which corresponds to cleavage by $\mathrm{XbaI}$ at codon 61 is diagnostic for the mutation. Using radioactive detection, mutant alleles can be detected at a frequency of $1: 10^{6}$ wild-type alleles. T7 DNA polymerase was used because errors generated by Taq polymerase created the $X b a I$ cleavage site at a frequency that interferes with the sensitivity that was reached. T7 DNA polymerase is presumably more accurate than Taq polymerase. ${ }^{(20)}$

Primers that contain mismatches can be used efficiently for PCR amplification. This opens the possibility for creating (or destroying) restriction enzyme recognition sites in PCR-amplified DNA. Also mismatch primers that yield (or destroy) a restriction enzyme recognition site in combination with the nucleotide sequence in the target DNA immediately downstream from the primer can be used. Point mutations at the specific sites in the target DNA then destroy (or create) the restriction enzyme recognition site and can thus be detected by restriction enzyme incubation and gel electrophoresis. Jiang et al. ${ }^{(30)}$ have used this mismatch primer approach to create a BstNI polymorphism for mutations at positions 1 and 2 of codon 12 of K-ras (the mutant DNAs are not cleaved). Kumar and colleagues $(31,32)$ have developed a sensitive method to detect $G$ to A mutations at position 2 of codon 12 of H-ras. An XmnI recognition site is created by the mutated codon 12 and mismatches in the $3^{\prime}$ oligonucleotide primer. After incubation with Xmnl, the amplified wild-type and mutant DNA fragments are detected by hybridization to a radioactive probe, followed by a gel retardation assay. Using this procedure, a ras oncogene can be iden- tified in a single cell mixed up with 10,000 normal cells. ${ }^{(31)}$ Mitsudomi and colleagues $^{(33)}$ have devised a large number of mismatch oligonucleotide primers that generate, in combination with different, specific ras gene point mutations, new restriction sites. Similarly, Jacobson and Moskovits ${ }^{(34)}$ have devised a set of primers that generate RFLPs for most of the known ras point mutations. In this approach the wild-type sequence is cleaved and the mutant sequence remains intact. The mismatch may be located near the $3^{\prime}$ end of one of the PCR primers, or can even be the 3 'nucleotide of a PCR primer, ${ }^{(34,35)}$ although it has also been reported that a mismatch at the 3 ' end of a primer stops the amplification process. $^{(36)}$

The nature of the point mutation detected by this primer-mediated RFLP analysis will be (mostly) known if a new cleavage site is generated by the mutation. ${ }^{(33)}$ Loss of the cleavage site requires additional analysis (ASO or sequence analysis of the restriction enzyme resistant PCR product) to determine the nature of the change in the DNA.

\section{Mutant-enriched PCR Amplification}

Recently, a primer-mediated RFLP method with enhanced sensitivity for the detection of mutant K-ras alleles has been devised. ${ }^{(37-39)}$ The high sensitivity is achieved by selective PCR of mutant K-ras gene sequences using a two-stage procedure (Fig. 1). First the DNA is amplified using a (mismatch) primer that generates a restriction enzyme recognition site only in combination with the wild-type sequence. Incubation with the restriction enzyme cleaves the amplified wild-type sequences and leaves the mutant sequences intact. Subsequently, the noncleaved mutant sequences are amplified in a second PCR using the same (mismatch) primer, incubated again

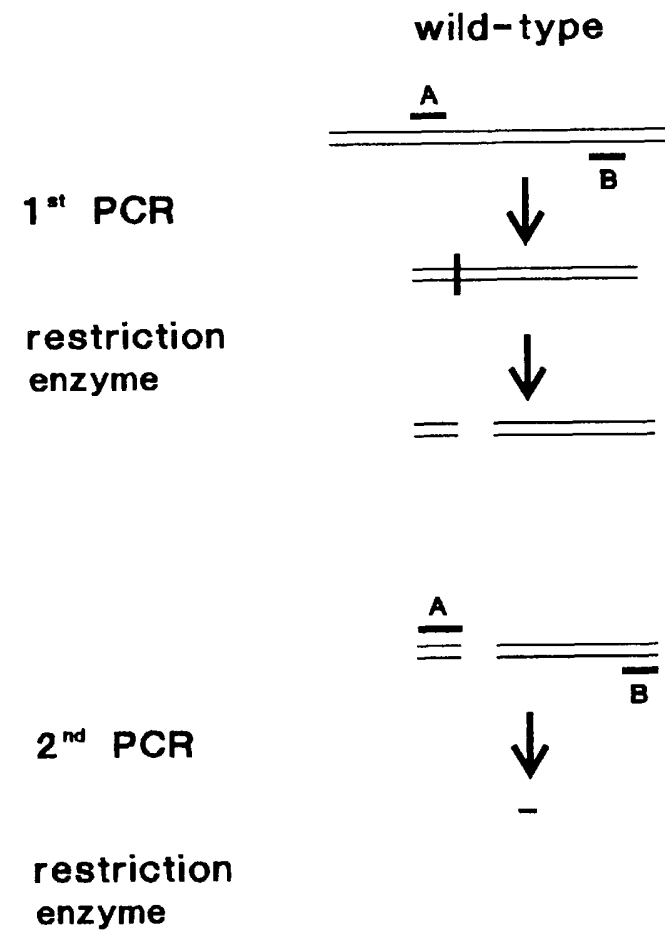

\section{mutant}
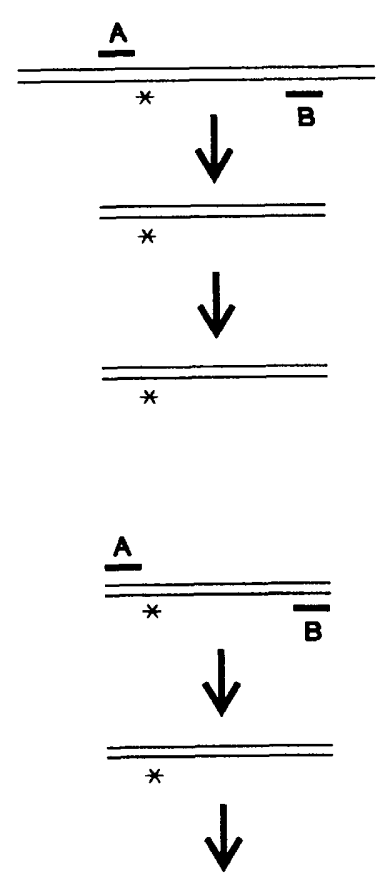

FIGURE 1 Mutant-enriched PCR amplification. The DNA, which may contain a mutation $\left(^{*}\right)$, is amplified using primers $A$ and $B$ (horizontal bars). Primer A may have 1- or 2-bp mismatches, which generate a restriction enzyme recognition site (vertical bar) in the wild-type allele but not in the mutant allele. Incubation with the restriction enzyme cleaves the amplified wild-type sequence and leaves mutant sequence intact. The same primers A and B are used in a second PCR, and now only the contiguous, uncleaved mutant sequence is amplified. The products of the second PCR are incubated with the restriction enzyme. The restriction enzyme-resistant DNA fragment is diagnostic for the presence of a mutant. 
with the restriction enzyme, and analyzed for RFLP. Restriction enzymeresistant PCR product, which can be detected by gel electrophoresis, is diagnostic for the presence of a mutation at the anticipated site. The nature of the mutant can then be determined by direct sequencing of the restriction enzyme-resistant material or by ASO of the mutant-enriched material obtained after the second amplification reaction (unpubl.). The sensitivity of this procedure is limited by the fidelity of the polymerase and the method of detection. However, if the number of cycles is kept low (12-15) in the first PCR of the procedure, a ras mutation occurring in 1 per 1000 cells can be detected by staining with ethidium bromide without detecting mutations introduced by Taq DNA polymerase during PCR. (37-39)

\section{Allele-specific PCR}

Allele-specific PCR is based on the exact complementarity between the template DNA and the primer. Templates that match the primer perfectly at the 3 ' terminal nucleotide are amplified efficiently, whereas no amplification is detected when there is a single mismatch at this position. ${ }^{(36,40,41)}$ Thus, allele-specific PCR can be performed using oligonucleotides whose 3 'terminal nucleotides correspond to specific point mutations. Ehlen and Dubeau ${ }^{(36)}$ and Stork et al. ${ }^{(42)}$ have used this approach successfully to detect ras mutations in cell lines and pancreas tumors. However, the conditions under which these allele-specific PCRs are performed are very critical, as shown by Kwok et al. ${ }^{(41)}$ and as may be concluded from the observations of Haliassos ${ }^{(35)}$ and Jacobson and Moskovits, ${ }^{(34)}$ who amplified ras gene segments efficiently using an oligonucleotide with a mismatch at the 3 ' terminal nucleotide.

\section{DIsCUSSION}

Mutations in one of the three ras genes are one of the most frequently occurring genetic events in human carcinogenesis known today, only outranked by mutations in the p53 gene. Therefore, the detection of mutations in ras genes will be a recurring analysis in a large number of laboratories. First, the detection of ras point mutations may be of prognostic or diagnostic significance. In this respect, the study of Rodenhuis and co-workers ${ }^{(43)}$ is worth mentioning because it shows that the presence of a mutation in the K-ras gene in adenocarcinoma of the lung is a marker for poor prognosis. Second, the characterization of genetic events underlying the development of a particular tumor may need the analysis of ras point mutations. Third, mutations in ras genes may be a useful marker for determining residual disease in leukemia, and, finally, mutations in ras genes may be indicative for the involvement of carcinogens. ${ }^{(1)}$

Not all procedures described in this review, however, are suitable for routine analysis, and the most appropriate procedure depends on the tumor type and the information necessary. For instance, ras point mutations in adeno-

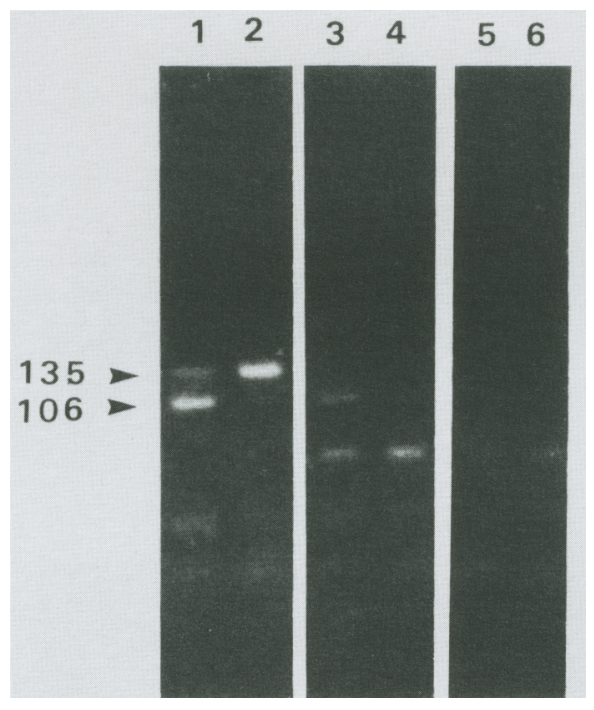

FICURE 2 RFLP analysis of mutant-enriched material (see also Fig. 1). K-ras DNA was amplified as described by Levi et al. ${ }^{(35)}$ Prior to the second PCR, samples were incubated with BstNI (even numbers) or not (odd numbers). After the second PCR, all samples were incubated with BstNI and analzyed by agarose gel electrophoresis in the presence of ethidium bromide. The positions of BstNI-resistant (135) and BstNI-cleaved (106) PCR products are indicated. The faster-migrating bands probably represent primer oligomers. (Lanes 1 and 2) Template DNA from a tumor containing a K-ras codon 12 mutation; (lanes 3 and 4) template DNA from a tumor which does not contain a K-ras codon 12 mutation; (lanes 5 and 6) no template DNA added. carcinoma of the pancreas and the lung occur almost exclusively in codon 12 of the K-ras gene. To detect these mutations, the most useful method is the restriction fragment length polymorphism (RFLP) analysis on mutantenriched PCR material (Fig. 2). This method is easy, fast, and reliable. Furthermore, it does not need radioactively labeled reagents, and is therefore very suitable for use in clinical laboratories. Finally, the method is very sensitive, allowing the detection of mutations in a background of normal tissue. In principle, this method can be used for most of the codons where mutations occur (see, for instance, ref. 34). This procedure, however, does not elude the exact mutation in the codon, information not necessary for the evaluation of the genetic events underlying tumor formation. RFLP analysis on mutant-enriched PCR material in combination with ASO may be the method of choice to determine the exact mutation.

DNA sequence analysis methods are very reliable procedures, providing that the majority of the tissue consists of tumor cells. The microsequencing procedure of Syvänen et al. ${ }^{(25)}$ allows detection of a mutation in a high background of wild-type sequences and sequence analysis of mutant-enriched PCR material is very sensitive as well. The RNase mismatch procedure and especially the SSCP procedure are more suitable for screening for mutations that can be located at different positions in a DNA segment, such as the mutations occurring in the p53 gene. For such analyses, direct sequencing is also very suitable and the method most used.

\section{ACKNOWLEDGMENTS}

We thank D.H.J. van Weering for valuable contributions and for Fig. 1 and Drs. P.D. Baas and B.M.Th. Burgering for a critical reading of the manuscript. This project is supported by the Dutch Cancer Society (K.W.F.).

\section{REFERENCES}

1. Bos, J.L. 1989. Ras oncogenes in human cancer: A review. Cancer Res. 49: 4682-4689.

2. Verlaan-de Vries, M., M.E. Boogaard, H. Van den Elst, J.H. Van Boom, A.J. Van der Eb, and J.L. Bos. 1986. A dot- 
blot screening procedure for mutated ras oncogenes using synthetic oligonucleotides. Gene 50: 313-320.

3. Wood, W.I., J. Gitschier, L.A. Lasky, and R.M. Lawn. 1985. Base composition-independent hybridization in tetramethylammonium chloride: A method for oligonucleotide screening of highly complex gene libraries. Proc. Natl. Acad. Sci. 82: 1585-1588.

4. Zhang, Y., M.Y. Coyne, S.G. Will, C.H. Levinson, and E.S. Kawasaki. 1991. Single-base mutational analysis of cancer and genetic diseases using membrane bound mofidied oligonucleotides. Nucleic Acids Res. 19: 3929-3933.

5. Myers, R.M., Z. Larin, and T. Maniatis. 1985. Detection of single base substitutions by ribonuclease cleavage at mismatches in RNA:DNA duplexes. Science 230: 1242-1246.

6. Winter, E., F. Yamamoto, C. Almoguera, and M. Perucho. 1985. A method to detect and characterize point mutations in transcribed genes: Amplification and overexpression of the mutant c-K-ras allele in human tumor cells. Proc. Natl. Acad. Sci. 82: 7575-7579.

7. Almoguera, C., D. Shibata, K. Forrester, J. Martin, and M. Perucho. 1988. Most human carcinomas of the exocrine pancraes contain mutant cK-ras genes. Cell 53: 549-554.

8. Perucho, M., K. Forrester, C. Almoguera, S. Kahn, C. Lama, D. Shibata, N. Arnheim, and W.E. Grizzle. 1989. Expression and mutational activation of the c-K-ras gene in human carcinomas. Cancer Cells 7: 137-141.

9. Hayashi, K. 1991. PCR-SSCP: A simple and sensitive method for detection of mutations in the genomic DNA. PCR Methods Applic. 1: 34-38.

10. Orita, M., Y. Suzuki, T. Sekiya, and K. Hayashi. 1989. Rapid and sensitive detection of point mutations and DNA polymorphisms using the polymerase chain reaction. Genomics 5: 874-879.

11. Orita, M., H. Iwahana, H. Kanazawa, K. Hayashi, and T. Sekiya. 1989. Detection of polymorphisms of human DNA by gel electrophoresis as singlestrand conformation polymorphisms. Proc. Natl. Acad. Sci. 86: 2766-2770.

12. Suzuki, Y., M. Orita, M. Shiraishi, K. Hayashi, and T. Sekiya. 1990. Detection of ras gene mutations in human lung cancers by single-strand conformation polymorphism analysis of polymerase chain reaction products. Oncogene 5: 1037-1043.

13. Suziki, Y., T. Sekiya, and K. Hayashi. 1991. Allele-specific polymerase chain reaction: A method for amplification and sequence determination of a single component among a mixture of sequence variants. Anal. Biochem. 192: 82-84.

14. Ainsworth, P.J., L.C. Surh, and M.B. Coulter-Mackie. 1991. Diagnostic single strand conformational polymorphism (SSCP): A simplified non-radioisotopic method as applied to a Tay-Sachs B1 variant. Nucleic Acids Res. 19: 405-406.

15. McMahon, G., E. Davis, and G.N. Wogan. 1987. Characterization of cKi-ras oncogene alleles by direct sequencing of enzymatically amplified DNA from carcinogen-induced tumors. Proc. Natl. Acad. Sci. 84: 4974-4978.

16. Collins, S.J. 1988. Direct sequencing of amplified genomic fragments documents $\mathrm{N}$-ras point mutations in myeloid leukemia. Oncogene Res. 3: 117123.

17. Luebbert, M., D. Jonas, C.W. Miller, F. Hermann, R. Mertelsman, F. McCormick, and H.P. Koeffler. 1990. Retro-spective analysis of ras gene activa-tion in myeloid leukemia cells. Oncogene 5: 583-587.

18. Burmer, G.C., P.S. Rabinovitch, and L.A. Loeb. 1989. Analysis of c-Ki-ras mutations in human colon carcinoma by cell sorting, PCR and direct sequencing. Cancer Res. 49: 2141-2146.

19. Gyllenstein, U.B. and H.A. Ehrlich. 1988. Generation of single-stranded DNA by the polymerase chain reaction and its application to direct sequencing of the HLA-DQA locus. Proc. Natl. Acad. Sci. 85: 7652-7656.

20. Keohavong, P. and W.G. Thilly. 1988. Fidelity of polymerases in DNA amplification. Proc. Natl. Acad. Sci. 86: 9253-9257.

21. Kretz, K.A., G.S. Carson, and J.S. O'Brien. 1989. Direct sequencing from low-melt agarose with Sequenase. Nucleic Acids Res. 17: 5864.

22. Mitchell, L.G. and C.R. Merril. 1989. Affinity generation of single-stranded DNA for dideoxy sequencing following the polymerase chain reaction. Anal. Biochem. 178: 239-242.
23. Hultman, T., S. Stahl, E. Hornes, and M. Ulhén. 1989. Direct solid phase sequencing of genomic and plasmid DNA using magnetic beads as solid support. Nucleic Acids Res. 17: 49374946.

24. Shaw, P., S. Tardy, E. Benito, A. Obrador, and J. Costa. 1991. Occurrence of $\mathrm{Ki}$-ras and p53 mutations in primary colorectal tumors. Oncogene 6: 2121-2128.

25. Syvänen, A.-C., H. Söderlund, E. Laasoken, M. Bengtström, M. Turunen, and A. Palotie. 1992. N-ras gene mutations in acute myeloid leukemia: Accurate detection by solid-phase minisequencing. Int. J. Cancer (in press).

26. Manam, S. and W.W. Nichols. 1991. Multiplex polymerase chain reaction amplification and direct sequencing of homologous sequences: Point mutation analysis of the ras genes. Anal. Biochem. 199: 106-111.

27. Feinberg, A., B. Vogelstein, M. Droller, S. Baylin, and B. Nelkin. 1983. Mutation affecting the 12th amino acid of the c-Ha-ras oncogene product occurs infrequently in human cancer. Science 220: 1175-1177.

28. Deng, G. 1988. A sensitive non-radioactive PCR-RFLP analysis for detecting point mutations at 12 th codon of oncogene c-Ha-ras in DNAs of gastric cancer. Nucleic Acids Res. 16: 6231.

29. Nakazawa, H., A.-M. Aguelon, and H. Yamasaki. 1990. Relationship between chemically induced Ha-ras mutation and transformation of BALB/c 3T3 cells: Evidence for chemical-specific activation and cell typespecific recruitment of oncogene in transformation. Mol. Carcinogen. 3: 202-209.

30. Jiang, W., S.M. Kahn, J.G. Guillem, S.-H. Lu, and I.B. Weinstein. 1989. Rapid detection of ras oncogenes in human tumors: Applications to colon, esophageal, and gastric cancer. Oncogene 4: 923-928.

31. Kumar, R., S. Sukumar, and M. Barbacid. 1989. Detection of ras oncogenes at the single-cell level. Cancer Cells 7: 151-156.

32. Kumar, R., S. Sukumar, and M. Barbacid. 1990. Activation of ras oncogenes preceding the onset of neoplasia. Science 248: 1101-1104.

33. Mitsudomi, T., J. Viallet, J.L. Mulshine, R.I. Linnoila, J.D. Minna, and 
A.F. Gazdar. 1991. Mutations of ras genes distinguish a subset of nonsmall-cell lung cancer cell lines from small-cell lung cancer cell lines. Oncogene 6: 1353-1362.

34. Jacobson, D.R. and T. Moskovits. 1991. Rapid, nonradioactive screening for activating ras oncogene mutations using PCR-primer introduced restriction analysis (PCR-PIRA). PCR Methods Applic. 1: 146-148.

35. Haliassos, A., J.C. Chomel, S. Grandjouan, J. Kruh, J.C. Kaplan, and A. Kitzis. 1989. Detection of minority point mutations by modified PCR technique: A new approach for a sensitive diagnosis of tumor-progression markers. Nucleic Acids Res. 17: 80938099.

36. Ehlen, T. and L. Dubeau. 1989. Detection of ras point mutations by polymerase chain reaction using mutation-specific, inosine-containing oligonucleotide primers. Biochem. Biophys. Res. Commun. 160: 441-447.

37. Kahn, S.M., W. Jiang, T.A. Culbertson, I.B. Weinstein, G.M. Williams, N. Timita, and Z. Ronai. 1991. Rapid detection and sensitive nonradioactive detection of mutant K-ras genes via "enriched" PCR amplification. Oncogene 6: 1079-1083.

38. Levi, S., A. Urbano-Ispizua, R. Gill, D.M. Thomas, J. Gilbertson, C. Foster, and C.J. Marshall. 1991. Multiple Kras codon 12 mutations in cholangiocarcinomas demonstrated with a sensitive polymerase chain reaction technique. Cancer Res. 51: 3497-3502.

39. Chen, J. and M.V. Viola. 1991. A method to detect ras point mutations in small subpopulations of cells. Anal. Biochem. 195: 51-56.

40. Wu, D.Y., L. Ugozzoli, B.K. Pal, and R.B. Wallace. 1989. Allele-specific enzymatic amplification of $\beta$-globin genomic DNA for diagnosis of sickle cell anemia. Proc. Natl. Acad. Sci. 86: 2757-2760.

41. Kwok, S., D.E. Kellogg, D. Spasic, L. Goda, C. Levenson, and J.J. Sninsky. 1990. Effects of primer-template mismatches on the polymerase chain reaction: Human immunodeficiency virus type 1 model studies. Nucleic Acids Res. 18: 999-1005.

42. Stork, P., M. Loda, S. Bosari, B. Wiley, $\mathrm{K}$. Poppenhusen, and $\mathrm{W}$. Wolfe. 1991. Detection of K-ras mutations in pancreatic and hepatic neoplasms by non-isotopic mismatched polymerase chain reaction. Oncogene 6: 857-862.

43. Slebos, R.J.C., R.E. Kibbelaar, O. Dalesio, A. Kooistra, J. Stam, C.J.L.M. Meijer, Sj.Sc. Wagenaar, R.G.J.R.A. Vanderschueren, N. van Zandwijk, W.J. Mooi, J.L. Bos, and S. Rodenhuis. 1990. Kirsten-ras oncogene activation as a prognostic marker in adenocarcinoma of the lung. N. Engl. I. Med. 323: 561-565. 


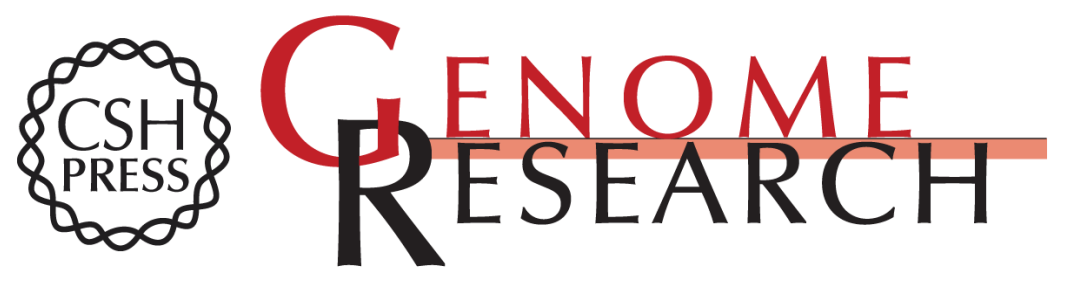

\section{PCR-based approaches for detection of mutated ras genes.}

$A$ D van Mansfeld and $J \mathrm{~L}$ Bos

Genome Res. 1992 1:211-216

Access the most recent version at doi:10.1101/gr.1.4.211

References This article cites 42 articles, 12 of which can be accessed free at:

http://genome.cshlp.org/content/1/4/211.full.html\#ref-list-1

\section{License}

Email Alerting Receive free email alerts when new articles cite this article - sign up in the box at the Service top right corner of the article or click here.

\section{Affordable, Accurate Sequencing.}

To subscribe to Genome Research go to: https://genome.cshlp.org/subscriptions 